\title{
An Author's Dilemma: Where to Publish?
}

You have got some exciting results from your study and you want to publish them. But where? First, let's think about why you want to publish these results. Is it so that the world can benefit from them? Is it to help you get the next grant, job or promotion? Is it so that others in the field read it and you can hear what they think? Your reasons can affect your choice of publication venue. You may think that getting your paper into a journal with the highest possible impact factor is your only concern.

Journals are the essence of scholarly communication. They not only serve to disseminate latest scientific advancements but also provide a platform for archiving scholarly information for future reference, and allow a researcher to assert his or her scientific caliber. Selecting the most suitable journal to showcase one's scholarly work is no mean feat. With more than 43,000 biomedical journals listed with PubMed ${ }^{1}$, the database maintained by United States National Library of Medicine (NLM), this exercise can easily baffle an inexperienced researcher. The huge risk of rejection of a paper from a journal that is not the right fit, and a widening web of dubious and predatory journals which publish almost everything sent to them, make this task particularly daunting. You may think that getting your paper into a journal with the highest possible impact factor is your only concern. However, this makes sense only if you think that you will be judged solely on the journal your paper is in rather than the quality and actual impact of the work. Although journal name and impact factor are still used to judge papers (or even researchers), the problems with this approach are becoming more widely known. ${ }^{2}$ Within one journal, papers can vary enormously in their quality and citations so it is unfair to judge a single paper by the mean number of citations in a whole journal.

\section{Where to Publish?}

Failure to choose the appropriate journal results in rejection and wastage of precious time, and slow career progress for the researcher. To facilitate the process of selecting the most appropriate journal, we need to consider the following variables (Box 1).

Focus: Every journal targets a certain audience and has a certain focus. On the basis of their focus, journals can be categorised as: broad-specialty vs specialty journals, pure research vs applied science journals, qualitative research vs quantitative research journals, veterinary (animal) science vs human science journals, etc. Likewise, some journals may have a more local and regional appeal, while others may have a more global readership. Specialised journals, even with a potentially smaller readership, may disseminate your work more efficiently to your desired audience than a broad- specialty journal. It is important to remember that we should not only be interested in getting our work published, but also aim to get it noticed by the right audience. Therefore, it makes sense to publish data pertaining to a regional community in a local journal where it may influence the practice and policy rather than publishing in a 'reputed' international journal that is seldom referred to by the endasers. For example, a research work evaluating the predictors of mortality in children suffering from dengue fever in an urban belt in India would be better appreciated and read in a journal popular (and published) in India rather than a foreign journal with very limited circulation in the region of the origin of work.

\section{BOX 1. Variables to consider for choosing a journal}

- $\quad$ Focus / Scope

- Indexing status

- Impact factor

- $\quad$ Peer-reviewed

- Affiliation to scientific societies
- Publication frequency

- Publication fees

- Accessibility

- Time to publication/Early online version 
The focus of the journal is usually stated on the journal's home page under the heading 'scope of the journal' or in the instructions to authors. A look at the recent issues of the journal will also give you an idea of the journal's area of focus. It is important to ascertain the harmony between the theme of the manuscript and focus of the journal before submission, as a mismatch between the two is one of the leading causes for outright rejection of the manuscript.

Indexing status: Indexing of a journal in a citation database is a property by the virtue of which articles published in it become searchable in that database. ${ }^{3}$ The content published in the journal is indexed at the article level by assigning keywords, and then making them searchable in the database. Other bibliographic elements of journal articles, including authors' names, title of the article, journal name, and date of publication, are also used for indexing.

Index Medicus was the most widely accepted and comprehensive database of biomedical journals from 1879 until 2004. With the rapidly increasing number of journals, the printed publication Index Medicus was replaced by its online version 'Medline' in 2005. Among the major databases for biomedical journals, indexing by Medline is considered as a benchmark of high quality for a journal. Over the years, other databases like Embase, Scopus, Science Citation Index, Directory of Open Access Journals, and many regional databases have emerged. Remember Google, Google Scholar and Sherpa-Romeo are not citation databases!

However, indexing of a journal comes with its own problems. Inclusion of a journal in a reputed indexing database depends on its scientific merit and rigorous publication policy and ethics, and therefore not all journals get indexed. Several regional and national journals, published in native languages, fail in their attempt to be indexed in the international databases. We must remember that not all research is relevant globally, and some may only be suited for publication in a regional or national journal that may not be indexed. Therefore, although important, indexing should not be used as the sole criterion for choosing the journal.

Impact Factor: Another parameter - the Impact Factor (IF) - is often used as a proxy for the relative importance of a journal within its field, and is frequently over-rated. IF of a journal is the annual measure of the extent to which articles published in that journal are cited. IF is awarded to the journals indexed in Science Citation Index, published annually in Thomson Reuters Journal Citation Reports. ${ }^{4}$ However, IF must be interpreted with caution as its calculations are prone to manipulation. ${ }^{5}$ Editorial policies such as preferential publication of review articles and articles dealing with newer diagnostics and therapeutics, short publication lag, and excessive self-citation can magnify the IF. English language journals and basic sciences journals have higher impact factors. Abuse of the IF and the dominance of the prominent journals is a threat to the smaller and non-English language journals, and is akin to the 'Matthew effect' whereby the rich get richer and the poor become poorer. Interestingly, IF is not available for all indexed journals as not all journals indexed in MedLine are indexed in the Science Citation Index. ${ }^{6}$ Moreover, the IF of a journal just tells about the merit of the journal, and not that of a particular article published in the journal.

Affiliation of the Journal to prestigious organisations: A journal publisher who is a member of the Committee on Publication Ethics (COPE) indicates that the journal will follow the essential norms on publication ethics. COPE is a platform for editors and publishers of peer reviewed journals to discuss and seek advice on the ethical issues of publishing. Another indicator of the journal quality is its affiliation to the International Committee of Medical Journal Editors (ICMJE) which would also indicate that the journal abides by the publication recommendations given by them. Open access journals listed in the Directory of Open Access Journals (DOAJ) and Open Access Scholarly Publisher's Association also signify its credibility. Journals owned by reputed scientific societies (academies) are perceived to be superior.

Peer review: Peer review process is a service rendered by reviewers who provide honest and constructive criticism of research work to assess it worthiness for publication in a journal. Hence, peer review process is vital element of scholarly publishing and peer-reviewed journals are considered honourable. ${ }^{7}$ 
Reputation among colleagues: A simpler way to assess the reputation of a journal could be asking your peers or mentor about their choice of journal.

Accessibility: Journals which have both print and online versions have easier accessibility and hence may be preferred. Journals providing free online content are more accessible, especially to readers from underprivileged settings. In addition, regional or national journals with English-translated versions may be globally more acceptable.

Time-to-print: Many journals declare the date of initial submission and the date of final acceptance at the time of final publication. Journals offering a reasonable time frame for publication should be preferred, lest the research becomes outdated. However, with rampant unethical publishing practices, authors need to be cautious while choosing to publish in journals offering fast-track publication as many of these may actually be predatory.

\section{REFERENCES}

1. U.S. National Library of Medicine. List of all journal cited in Pubmed $囚$. Available from: https://www.nlm.nih.gov/ bsd/serfile_addedinfo.html. Accessed January 9, 2016.

2. Just Say No to Impact Factors. The Guardian. http://www.theguardian. com/science/political-science/2013/may/17/ science-policy (cited May 2014).

3. Ng KH, Peh WC. Getting to know journal bibliographic databases. Singapore Med J. 2010;51:757-60; quiz 761.

4. Garfield E. The history and meaning of the journal impact factor. JAMA. 2006;295:90-3. DOI: https://doi.org/ 10.1001/jama.295.1.90

5. Lippi G, Favalor EJ, Simundic AM. Biomedical research platforms and their influence on article submissions and journal rankings: An update. Biochem Med (Zagreb). 2012;22:7-14. DOI: https://doi.org/10.11613/BM.2012.002

6. Elsaie ML, Kammer J. Impactitis: The impact factor myth syndrome. Indian J Dermatol. 2009;54:83-5. DOI: https://doi.org/10.4103/0019-5154.48998

7. Hojat M, Gonnella JS, Caelleigh AS. Impartial judgment by the "gatekeepers" of science: Fallibility and accountability in the peer review process. Adv Health Sci Educ Theory Pract. 2003;8:75-96. DOI: https://doi.org/ 10.1023/A:1022670432373

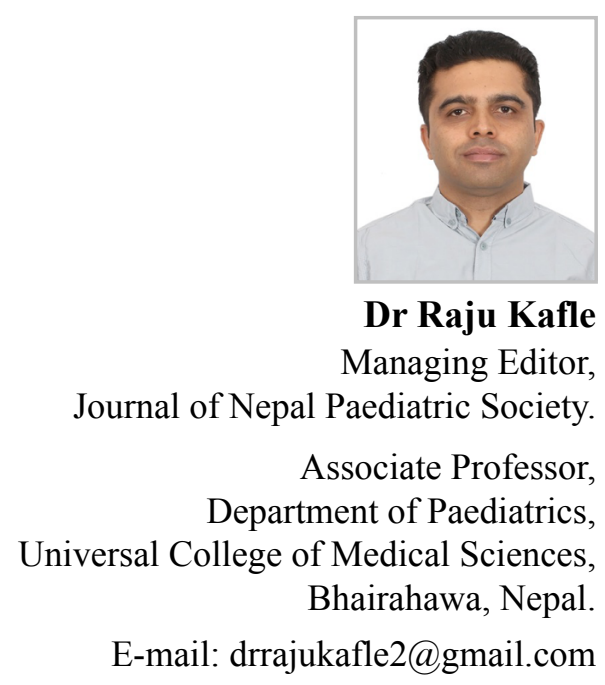

DOI: http://dx.doi.org/10.3126/mjsbh.v19i2.29327

Submitted on: $2020-06-06$

Accepted on: 2020-06-26

This work is licensed under creative common license:

http://creativecommons.org/licenses/by-nc-nd/4.0/ @ MJSBH 2020 